\section{EDUCAÇ̃̃O}

Número Temático - vol. 10 n. 1 - 2020

ISSN Digital: 2316-3828

ISSN Impresso: 2316-333X

DOI: 10.17564/2316-3828.2020v10n1p211-226

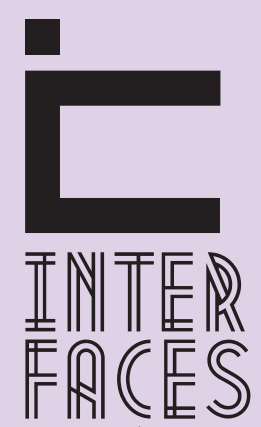

CIENTÍFICAS

\title{
AMBIENTES DIGITAIS DE APRENDIZAGEM E COMPETÊNCIAS DIGITAIS: CONHECER O PRESENTE PARA AGIR NUM FUTURO PÓS-COVID
}

\section{DIGITAL LEARNNG ENVIRONMENTS AND DGGTAL SKLLLS: KNOWING THE PRESENT TO ACT IN A POST-COVID FUTURE}

\section{ENTORNOS DE APRENDIZA E Y HABLLIDADES DIGITALES: CONOCER AL PRESENTE PARA ACTUAR EN UN FUTURO POSCOVID}

Marcos Andrei Ota ${ }^{1}$ Sara Dias-Trindade 2

\section{RESUMO}

O impacto causado pela pandemia de COVID-19 no âmbito do ensino superior tem desafiado muitos professores a ressignificarem suas práticas pedagógicas, sobretudo, pela necessidade de desenvolver situações de aprendizagem em ambientes digitais. Para tal desafio, torna-se essencial a aquisição de competências digitais e a criação de programas de formação docente que possam caminhar na mesma direção em prol da construção de modelos educacionais de qualidade. Nesse sentido, este estudo visa apresentar os resultados do projeto em curso que tem por base o questionário DigCompEdu CheckIn, na versão validada em Portugal. Trata-se de uma pesquisa de natureza qualitativa e exploratória. A coleta de dados foi realizada antes do início do isolamento social, contemplando um total de 102 professores que atuam em modalidades de cursos superiores. Para compor a análise dos resultados, foram observados os 21 itens de competência digital, distribuídos nas 6 Áreas do instrumento para então, compreender o nível de proficiência digital do perfil da amostra. Dos resultados obtidos, destacam-se o mapeamento dos resultados globais dos participantes (Nível B1 - Integrador) e análise das áreas que apresentaram pontos fortes e aspectos de maior fragilidade. Relativamente aos resultados, percebe-se que recorrer ao instrumento possibilita identificar quais competências os docentes carecem de maior atenção e investimento formativo, essencial num tempo de instabilidade e que pode ter no Digital o meio de assegurar que a Educação nunca para.

\section{PALAVRAS-CHAVE}

Formação de Professores. COVID-19. Competências Digitais. Tecnologias Digitais. Ensino Superior. 


\section{ABSTRACT}

The impact caused by the COVID-19 pandemic in the context of higher education has challenged many teachers to rethink their pedagogical practices, mainly due to the need to develop learning situations in digital environments. For such a challenge, it is essential to acquire digital competencies and create teacher training programs that can move in the same direction in favor of building quality educational models. In this sense, this study aims to present the results of the current project that is based on the DigCompEdu CheckIn questionnaire, in the version validated in Portugal. It is a qualitative and exploratory research. Data collection was carried out before the beginning of social isolation, covering a total of 102 teachers working in higher education courses. To compose the analysis of the results, the 21 items of digital competence were observed, distributed in the 06 Areas of the instrument to then understand the level of digital proficiency of the sample profile. From the results obtained, the mapping of the global results of the participants (Level B1 - Integrator) and analysis of the areas that presented strengths and weaknesses in each scenario. Regarding the results, the instrument makes it possible to identify which competencies teachers need more attention and training investment, essential in a time of instability and in which Digital can be the means to ensure that Education never stops.

\section{KEYWORDS}

Teacher Training. COVID-19. Digital Competences. Digital Technologies. Higher Education.

\section{RESUMEN}

El impacto causado por la pandemia de COVID-19 en el contexto de la educación superior ha desafiado a muchos maestros a repensar sus prácticas pedagógicas, principalmente debido a la necesidad de desarrollar situaciones de aprendizaje en entornos digitales. Para tal desafío, es esencial adquirir competencias digitales y crear programas de capacitación docente que puedan moverse en la misma dirección a favor de la construcción de modelos educativos de calidad. En este sentido, este estudio tiene como objetivo presentar los resultados del proyecto actual que se basa en el cuestionario DigCompEdu CheckIn, en la versión validada en Portugal. Es una investigación cualitativa y exploratoria. La recopilación de datos se realizó antes del comienzo del aislamiento social, cubriendo un total de 102 docentes que trabajan en cursos de educación superior. Para componer el análisis de los resultados, se observaron los 21 ítems de competencia digital, distribuidos en las 06 áreas del instrumento para luego comprender el nivel de competencia digital del perfil de la muestra. A partir de los resultados obtenidos, el mapeo de los resultados globales de los participantes (Nivel B1 - Integrador) y el análisis de las áreas que presentaron fortalezas y debilidades en cada escenario. En cuanto a los resultados, el instrumento permite identificar qué competencias los docentes necesitan más atención 
e inversión en capacitación, esenciales en un momento de inestabilidad y en las que lo Digital puede ser el medio para garantizar que la educación nunca se detenga.

\section{PALABRAS CLAVES}

Formación del Profesorado; COVID-19; Competencias Digitales; Tecnologías Digitales; Educación Superior.

\section{INTRODUÇÃO}

O potencial das Tecnologias Digitais da Informação e da Comunicação (TDIC) tem trazido novos desafios aos professores, tornando essencial a aquisição de competências que lhes permitam usar de modo efetivo essas mesmas tecnologias. Nos tempos atuais, a pandemia do COVID-19 veio demonstrar a necessidade de conseguir dar continuidade aos processos educacionais por meio de mecanismos digitais. Porém, é importante compreender, primeiro, o nível de competências digitais que podem ter os docentes, para em função dessa realidade conseguir, primeiro, preparar formação que contribua para suprir essas necessidades e, em seguida, conseguir construir cenários educativos de qualidade.

Em um tempo de incertezas face aos futuros cenários da educação assume particular importância que todos os atores do processo educativo tenham competências digitais e as saibam utilizar nas diferentes etapas do ensino e da aprendizagem. Tal afirmação, corrobora para uma movimentação de estudos (FERDIG et al., 2020; GARCÍA-PEÑALVO et al., 2020; PIMENTEL et al., 2020) que buscam relatar as experiências vividas durante o período de isolamento social, tais contribuições intensificam ainda mais a necessidade de refletir sobre as competências requeridas; não só a nível da inclusão e utilização das TDIC no processo educativo, mas também a nível da sua utilização pedagógica, envolvendo e capacitando os estudantes para o seu uso, no sentido do que vários autores designam como «fluente digital» (MILLER; BARTLET, 2012; WHITE, 2013; SPARROW, 2018; DIAS-TRINDADE; FERREIRA, 2020).

As entidades públicas devem analisar dados como os que este estudo vem apresentar para pensar políticas públicas que façam frente à importância de uma Escola que, juntamente com as infraestruturas e os instrumentos tecnológicos e digitais que, claramente, têm de se fazer parte da realidade, precisa também estar devidamente capacitada para um uso pedagógico do digital.

Nesse sentido, este texto visa apresentar os resultados do projeto em curso que tem por base o questionário DigCompEdu Check/n, na versão validada em Portugal (DIAS-TRINDADE; MOREIRA; NUNES, 2019), mostrando o nível de competências digitais dos professores antes do início da pandemia de COVID-19. A partir dos resultados obtidos, pretende-se explicar quais as áreas que carecem de maior investimento ao nível de formação, sobretudo tendo em conta a realidade vivida no mundo e a necessidade de habilitar os docentes não só para a educação emergencial ou remota atualmente vivida, mas, sobretudo, pensando no futuro. 


\section{AMBIENTES DIGITAIS DE APRENDIZAGEM E COMPETÊNCIAS DIGITAIS}

O crescente uso das TDIC no processo educativo tem impulsionado novas formas de ensinar e de aprender, impondo aos educadores o desenvolvimento de competências digitais para alcançar os objetivos pedagógicos desejados. Nesse sentido, as universidades vêm-se adaptando cada vez mais a um mundo digital, fazendo com que recursos e equipamentos outrora encarados apenas como sociais ou lúdicos comecem a ganhar mais espaço nas salas de aula, contribuindo para criar novos espaços educativos, formais, não formais ou mesmo informais.

Assim, é cada vez mais importante repensar os processos educativos e estabelecer novas formas de desenhar a forma como a aprendizagem pode ocorrer. De fato, a aprendizagem ocorre, cada vez mais, numa mistura de espaços, presenciais e/ou a distância, estando hoje professores e estudantes imersos numa cultura digital que leva a uma vivência onlife (FLORIDI, 2015). É por isso que centramos a nossa atenção no desenvolvimento de competências para funcionar numa educação digital, aberta e em rede, aliando as naturais práticas educacionais entendidas como práticas de socialização, aos benefícios que podem ser encontrados na utilização da tecnologia digital.

No caso concreto do Ensino Superior, a aposta numa formação pedagógica não tem estado entre as principais preocupações das instituições universitárias, simplesmente por se considerar que a docência é uma atividade eminentemente prática para a qual não serão necessários conhecimentos muito específicos (ZABALZA, 2004; PRETTO; RICCIO, 2010). Porém, novos desafios têm surgido, colocando em perspetiva a forma como se ensina nas universidades, que cada vez mais precisam rever as suas pedagogias e a sua didática, proporcionando novas formas de acesso ao conhecimento e à formação por parte dos seus estudantes com a adição de metodologias e práticas de ensino que fomentem a criatividade, o espírito crítico e a capacidade de trabalho efetivo por parte dos seus estudantes.

Perante os acontecimentos dos últimos meses e a incerteza sobre a continuidade desta situação, afigura-se fundamental que os docentes tenham uma clara consciência de como podem utilizar e integrar as tecnologias digitais nos mais diversos momentos da sua atividade profissional, para preparar e executar estratégias pedagógicas onde o digital contribui de forma efetiva para o desenvolvimento das aprendizagens. Um dos fatores mais importantes nesta questão prende-se com a capacidade de perceber que a competência digital é um constructo em constante evolução.

É, pois, fundamental ter consciência dessa mesma evolução, de que em umas áreas pode o docente encontrar-se mais próximo da literacia digital (ou seja de um estádio inicial onde se compreende que a tecnologia digital pode contribuir para a estruturação de ambientes de aprendizagem de qualidade e se sabe colocar essas ideias em prática) ou, em outras áreas, aproximar-se da fluência digital (a capacidade não só de saber fazer o quê com a tecnologia digital para atingir determinado objetivo, mas também saber como o fazer da melhor forma possível).

Em vésperas da pandemia de COVID-19 levar ao encerramento de Universidades em todo o mundo, realizou-se um inquérito baseado no questionário DigCompEdu CheckIn validado para a população portuguesa por Dias-Trindade, Moreira e Nunes (2019) que permite obter uma percepção dos docentes sobre as suas competências digitais. 
Este instrumento permite, sobre essas mesmas percepções, efetuar um diagnóstico sobre o nível de competência digital em que se encontram, em que áreas existem mais dificuldades e sobretudo, perante a realidade atual, traçar um cenário formativo que possibilite a capacitação dos docentes do Ensino Superior para melhor conseguirem enfrentar as necessidades atuais de um ensino eventualmente restringido a ambientes digitais, mas, em um futuro que se deseja próximo, fazer uso destas as competências digitais adquiridas por meio de formação adequada às suas necessidades em ambientes de ensino e de aprendizagem híbridos, onde o digital seja utilizado, em diferentes etapas do processo educativo, como um potenciador das aprendizagens dos estudantes.

\section{MÉTODOS}

Nesta seção, são apresentados o método e instrumento DigCompEdu Check/n como forma de evidenciar em nosso estudo as questões relacionadas ao nível de competência digital. A saber, seguindo o protocolo do comitê de ética institucional e de forma anônima, cada respondente ao instrumento forneceu seu consentimento para participação do estudo.

\subsection{CARACTERIZAÇ̃̃O DOS PARTICIPANTES}

O estudo em questão está ancorado por uma pesquisa qualitativa e exploratória, realizado em fevereiro de 2020, um mês antes à mobilização de isolamento social em decorrência da pandemia do COVID19. A população deste estudo é representada por docentes, coordenadores e tutores de instituição de ensino superior privado. Um total de 122 professores recebeu o instrumento durante a semana de formação docente, que na ocasião, abordara o design da aprendizagem ativa e a dinamização dos espaços de aprendizagem como temas centrais. $0 \mathrm{~N}$ da amostra corresponde a 102 (83\%) participantes que concluíram o preenchimento, número esse considerado adequado para análise amostral.

Ao analisar os dados da amostra, 61,8\% ( $N=63)$ são do gênero feminino e 38,2\% $(N=39)$, do gênero masculino. Em relação à idade, é possível dividir em cinco grupos de faixa etária: $11,76 \%(\mathrm{~N}=12)$ tem entre 22 e 29 anos, 36,27\% ( $N=37)$ está entre 30 e 39 anos, seguido de $25,49 \%(N=26)$ de 40 a 49 anos, seguido de $21,57 \%(\mathrm{~N}=22)$ entre 50 e 59 anos e finalmente $4,9 \%(\mathrm{~N}=5)$ de 60 a 70 anos. Diante das informações obtidas, observa-se um predomínio de docentes do segundo grupo (30-39 anos).

0 perfil dos participantes está caracterizado como docentes que, em teoria, tem familiaridade com uso de ambientes virtuais, sendo que $94,1 \%(\mathrm{~N}=96)$ atuam em cursos totalmente a distância, $42,2 \%(N=43)$ em cursos presenciais e $19.6 \%(N=20)$ lecionam em cursos superiores híbridos. Dentre as funções exercidas, a representatividade está distribuída em tutores de cursos a distância (61.8\% $\mathrm{N}=63)$, professores $(41.2 \% \mathrm{~N}=42)$ e coordenadores de curso $(15,7 \% \mathrm{~N}=16)$.

Com relação ao tempo de experiência dos docentes, $21,6 \%(\mathrm{~N}=22)$ revelaram ter mais de 20 anos de docência, 16,7\% ( $\mathrm{N}=17)$ entre 15 e 19 anos, 10,8\% ( $\mathrm{N}=11)$ de 10 a 14 anos,14,7\% ( $\mathrm{N}=15)$ com 6 a 9 anos de prática, $16,7 \%(\mathrm{~N}=17)$ com experiência docente entre 4 e 5 anos e por fim 19,6\% $(\mathrm{N}=20)$ entre 1 e 3 anos. 
Ainda no campo da experiência, quando questionados sobre a adoção de tecnologias digitais como ferramenta de ensino, os docentes em sua maioria, $66 \%(\mathrm{~N}=66)$, as utilizam no intervalo de 1 e 9 anos, $20 \%(\mathrm{~N}=20)$ entre 10 e 19 anos e $13 \%(\mathrm{~N}=13)$ com menos de um ano. Superior a 19 anos foi constatado apenas $3 \%(\mathrm{~N}=3)$.

Por fim e não menos importante, os docentes participantes apontaram ter como perfil de atendimento, estudantes, predominantemente de graduação $67.6 \%(\mathrm{~N}=69)$ e de licenciaturas $47.1 \%(\mathrm{~N}=48)$.

\subsection{INSTRUMENTO DIGCOMPEDU CHECKIN}

Como já mencionado, recorreu-se à escala de autoavaliação de competências digitais desenvolvida pelo EU Science Hub e ao estudo validado por Dias-Trindade e outros autores (2019) concebido para avaliar as competências digitais dos docentes portugueses.

Ressalta-se que a ferramenta inicial foi concebida a partir da colaboração de diversos países europeus, objetivando identificar o nível de competência digital docente, contemplando diferentes níveis de ensino, sendo um recurso de autorreflexão que possibilita aos docentes aprenderem mais sobre os seus pontos fortes pessoais e as áreas onde pode melhorar a utilização que faz das tecnologias digitais para os processos de ensino e aprendizagem.

Muito mais que reunir um conjunto de competências, o instrumento traz consigo um relatório que dá a conhecer, a partir das respostas, recomendações para melhorar as práticas já desenvolvidas (DIAS-TRINDADE et al., 2019). Os referidos autores complementam ainda sobre a relevância do instrumento, pois permite aos utilizadores perceberem que tipo de formação se faz necessário para avançar de nível.

A fim de contextualizar o leitor, este estudo exploratório foi baseado no instrumento (escala) adaptado e validado por Dias-Trindade e outros autores (2019) que reúne 21 itens distribuídos e reorganizados em seis áreas de competência do instrumento original (FIGURA 1). 
Figura 1 - Áreas e Âmbito do DIGCOMPEDU

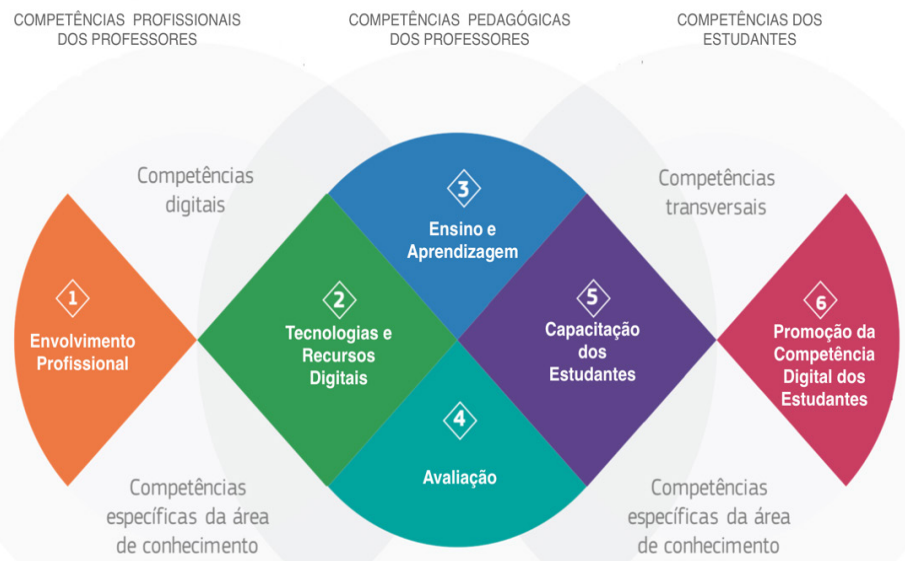

Fonte: Dias-Trindade, Moreira e Nunes (2019).

Cabe ressaltar que as respectivas áreas estão alocadas em três dimensões: Competências Profissionais dos Professores, Competências Pedagógicas dos Professores e Competências dos Estudantes.

- Área 1 (A1) Envolvimento profissional - uso de tecnologias digitais para comunicar, colaborar e promover o desenvolvimento profissional;

- Área 2 (A2) Tecnologias e Recursos digitais - uso de tecnologias para selecionar, criar e partilhar recursos digitais;

- Área 3 (A3) Ensino e aprendizagem - capacidade de gerir e organizar o uso de tecnologias digitais no processo de ensino e aprendizagem;

- Área 4 (A4) Avaliação - forma de recorrer às tecnologias digitais para avaliar e/ou melhorar os processos avaliativos dos estudantes;

- Área 5 (A5) Capacitação dos estudantes - uso das tecnologias para melhorar a inclusão, personalização, engajamento dos estudantes;

- Área 6 (A6) Promoção da competência digital dos estudantes - subsidiar os estudantes no uso das tecnologias digitais de forma criativa e responsável.

Na Tabela 1, tem-se a representação do nível de proficiência digital, permitindo aos docentes perceberem, de forma geral, seis níveis de proficiência. Ademais, para cada área, os utilizadores recebem feedbacks e orientações de como fazer para avançar nos conhecimentos das competências elencadas. A apresentação parcial dos resultados por área, possibilita insights oportunos para que os docentes possam compreender os pontos de melhorias e refletir sobre as recomendações dadas para cada cenário. 
Tabela 1 - Níveis de Competência Digital | DigCompEdu Check/n

\section{Nível de Competência Digital}

\begin{tabular}{|c|c|}
\hline A1 - Recém-chegados & menos de 19 pontos \\
\hline A2 - Exploradores & entre 19 e 32 pontos \\
\hline B1 - Integradores & entre 33 e 47 pontos \\
\hline B2 - Especialistas & entre 48 e 62 pontos \\
\hline C1 - Líderes & entre 63 e 77 pontos \\
\hline C2 - Pioneiros & mais de 77 pontos \\
\hline
\end{tabular}

Fonte: Dias-Trindade, Moreira e Nunes (2019, p. 158).

Cabe ressaltar que ao finalizar o preenchimento do instrumento DigCompEdu Check/n, o utilizador recebe um relatório com a pontuação geral, incluindo também uma descrição bem detalhada sobre o que representa cada um dos 6 níveis de competência digital (TABELA 1).

Ao recorrer o instrumento, a estratégia adotada tinha como intenção primária investigar aspectos de competências digitais docentes para atuação em diferentes espaços de aprendizagem, tendo em vista que os participantes, atuam em diferentes modalidades de cursos superiores (presencial, totalmente a distância e híbrido). Além disso, alguns objetivos adicionais foram incorporados para obtenção de dados sobre perfil docente, contexto e tempo de experiência com uso de tecnologias digitais, em especial, ambientes virtuais e uso de dispositivos mobile, participação de projetos de inovação educacional, formas de planejar e avaliar uma aula com recursos tecnológicos, nível de conhecimento sobre metodologias ativas.

Importa notar que, muito embora há quem diga que a pandemia acelerou o uso de tecnologias nos processos de ensino e aprendizagem, faz-se necessário compreender quais são as reais necessidades apresentadas pelos docentes.

\section{RESULTADOS}

A partir da análise dos resultados obtidos com o instrumento DigCompEdu CheckIn, foi possível identificar quais competências apresentaram maior ou menor fragilidade (TABELA 2). Esses indicadores representam uma análise oportuna para se observar pontos de maior atenção para que os participantes possam avançar para o nível seguinte da proficiência digital.

Observando o contexto do perfil da amostra (professores de cursos superiores a distância, tutores, professores de cursos presenciais e de cursos híbridos), tem-se um campo vasto para explorar as especificidades e necessidades de cada grupo, uma vez que, independentemente da modalidade, todos têm em comum, a exploração do uso de ambientes virtuais de aprendizagem.

Tal fato fora intensificado pelo ensino remoto emergencial em decorrência da pandemia, se for considerado o contexto de cursos superiores ofertados presencialmente e de forma híbrida. 
Ademais, os dados em questão possibilitam uma visão global sobre qual(is) competência(s) carecem maior atenção. 0 resultado geral da amostra revelou que o nível de competência predominante por área, foi o B1 - Integrador.

Tabela 2 - Resultado gerais da amostra - Nível de competência por área

\begin{tabular}{|c|c|c|c|c|}
\hline & Áreas & Itens de Competências & $\begin{array}{c}\text { Média de } \\
\text { Competência }\end{array}$ & $\begin{array}{c}\text { Nivel de } \\
\text { Competência }\end{array}$ \\
\hline \multirow[t]{2}{*}{ 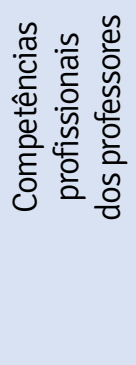 } & $\begin{array}{l}\text { Envolvimento } \\
\text { profissional }\end{array}$ & $\begin{array}{l}\text { Comunicação organizacional } \\
\text { Prática reflexiva } \\
\text { Competências digitais } \\
\text { Seleção }\end{array}$ & $\begin{array}{c}2,12 \\
2,28 \\
2,69 \\
2\end{array}$ & B1 \\
\hline & $\begin{array}{l}\text { Tecnologias e } \\
\text { Recursos digitais }\end{array}$ & $\begin{array}{l}\text { Colaboração Profissional } \\
\text { Gestão, proteção e partilha }\end{array}$ & $\begin{array}{l}2,02 \\
1,66\end{array}$ & B1 \\
\hline \multirow{9}{*}{ 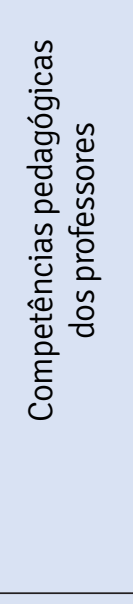 } & \multirow{4}{*}{$\begin{array}{c}\text { Ensino e } \\
\text { Aprendizagem }\end{array}$} & Ensino & 2,29 & \multirow{4}{*}{ B1 } \\
\hline & & Aconselhamento & 2,66 & \\
\hline & & Aprendizagem colaborativa & 2,26 & \\
\hline & & $\begin{array}{l}\text { Diferenciação e personalização } \\
\text { Criação de Conteúdo }\end{array}$ & $\begin{array}{l}1,61 \\
2,16\end{array}$ & \\
\hline & \multirow{3}{*}{ Avaliação } & Aprendizagem autorregulada & 1,85 & \multirow{3}{*}{ B1 } \\
\hline & & Estratégias de avaliação & 1,96 & \\
\hline & & Feedback e planejamento & 2,04 & \\
\hline & \multirow{2}{*}{$\begin{array}{l}\text { Empoderamento } \\
\text { dos Estudantes }\end{array}$} & Análise de evidências & 1,7 & \multirow{2}{*}{ B1 } \\
\hline & & Acessibilidade e inclusão & 2,2 & \\
\hline \multirow{5}{*}{ 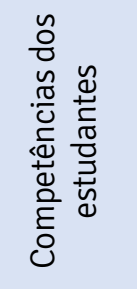 } & \multirow{5}{*}{$\begin{array}{c}\text { Promoção das } \\
\text { competências } \\
\text { digitais dos } \\
\text { estudantes }\end{array}$} & Motivação ativa dos estudantes & 1,75 & \multirow{5}{*}{ B1 } \\
\hline & & Informação e literacia midiática & 2,31 & \\
\hline & & Comunicação & 1,99 & \\
\hline & & Uso responsável & 1,88 & \\
\hline & & Resolução de problemas & 2,14 & \\
\hline
\end{tabular}

Fonte: Adaptado de Dias-Trindade e Ferreira (2020). 
Observa-se, analisando em detalhe cada uma das 21 competências, na Tabela 3, que oito delas apresentam valores mais baixos (entre 1,61 e 1,99 pontos), a saber:

Tabela 3 - Competências com indicadores mais baixos

\begin{tabular}{|c|c|c|}
\hline Dimensões & Áreas & Competências \\
\hline \multirow{2}{*}{$\begin{array}{c}\text { Competências } \\
\text { pedagógicas dos } \\
\text { professores }\end{array}$} & Tecnologias e Recursos Digitais & Gestão, proteção e partilha \\
\cline { 2 - 3 } & Ensino e Aprendizagem & Diferenciação e personalização \\
\cline { 2 - 3 } & Avaliação & $\begin{array}{c}\text { Aprendizagem autorregulada } \\
\text { Estratégias de avaliação }\end{array}$ \\
\hline \multirow{2}{*}{$\begin{array}{c}\text { Competências dos } \\
\text { estudantes }\end{array}$} & $\begin{array}{c}\text { Promoção da competência digital dos } \\
\text { estudantes }\end{array}$ & $\begin{array}{c}\text { Análise de Evidêneçacias } \\
\text { Como ativa dos estudantes } \\
\text { Comicação }\end{array}$ \\
\hline
\end{tabular}

Fonte: Autores.

Numa visão geral, as dimensões Competências Pedagógicas dos Professores e Competências dos Estudantes fornecem insights para as necessidades de formação dos professores participantes, com atenção especial, aos itens Diferenciação e Personalização (Área 3) - 1,61 pontos, seguidos pelas competências Gestão, proteção e partilha (Área 2) - 1,66 pontos e Análise de Evidências (Área 5) - 1,70 pontos.

Ao analisar as competências com valores mais elevados na amostra, tem-se as Áreas 1, 3 e 6 com indicadores de 2,26 a 2,69 pontos.

- Competências Digitais (Área 1) - 2,69

- Aconselhamento (Área 3) - 2,66

- Informação e literacia midiática (Área 6) - 2,31

- Ensino (Área 3) - 2.29

- Prática reflexiva (Área 1) - 2,28

- Aprendizagem colaborativa (Área 3) - 2,21

\section{DISCUSSÃO}

Os resultados gerados pelo instrumento representam vantagens tanto de ordem coletiva, se pensado de forma institucional quanto individual, se refletida pelo docente, uma vez que possibilita empenhar esforços, dando prioridade ao desenvolvimento de competências digitais, que se apresentaram mais frágeis por meio dos indicadores.

Ao se observar os valores gerais da amostra (TABELA 2) nota-se a predominância do nível de competência B1 (Integradores) em todas as áreas. Pensando no foco dado à utilização das tecnologias digitais em cada uma das 6 áreas do instrumento, pertencer ao nível Integrador para as questões das práticas 
de ensino, representa um perfil de profissionais que estão numa fase de integrar as tecnologias digitais nos processos de ensino e aprendizagem. Dias-Trindade e outros autores (2020) salientam que o instrumento não delimita apenas ao professor a identificação do nível atual da competência, mas também perceber que se faz necessário para avançar de nível e quais aspectos podem ser melhorados.

O enquadramento do grupo investigado no nível B1 em sua maioria, é justificado pelos autores do instrumento como algo normal, todavia não espera que se tenha resultados elevados de A1 e/ou C2. Os desafios trazidos pela pandemia, o ensino remoto emergencial se apresenta como ponto de partida para que os docentes de nível Integrador utilizem a criatividade para melhorar diversos aspectos, em especial os que despertam a colaboração e a promoção do engajamento dos estudantes.

Certamente, este perfil busca incorporar em suas práticas uma gama de tecnologias digitais, todavia, o que, de fato, os colocará no próximo nível (B2) vai além da adoção, faz-se necessário momentos de reflexões e trocas de conhecimentos para que a partir da escolha de um determinado recurso, possa atribuir uma intencionalidade pedagógica. Dito de outra forma, é necessário ampliar a compreensão sobre quais ferramentas são mais adequadas para as situações de aprendizagem em questão.

Voltando as atenções para o ensino remoto, tem-se, portanto, uma reflexão oportuna para a escolha das tecnologias que melhor se encaixam aos momentos síncronos e assíncronos. Repensar os espaços de aprendizagem, alinhar o uso das tecnologias digitais ao que se pretende ensinar e melhorar no âmbito profissional permite ao docente de nível B1 a progressão contínua dos níveis de proficiência digital, sobretudo, não apenas para as habilidades de lecionar no ensino remoto, mas para uma perspectiva do que se espera da educação, pós-Covid19.

Ao relacionar o perfil dos professores participantes aos pontos de maior fragilidades (TABELA 3) com destaque para o item de competência Diferenciação e Personalização (Área 3) pode-se, por exemplo, pensar em intensificar os esforços em modelos de formação que possam contemplar em suas temáticas, o uso avançado de ambientes virtuais para os momentos assíncronos, com a criação de conteúdo adaptativo a fim de personalizar a aprendizagem dos estudantes.

Além disso, pode-se ainda explorar o uso de regras para apresentação de conteúdo, diferentes formas de avaliação (revisão por pares ou rubricas), criação de exercícios atrelado às competências e uso de metodologias ativas em contextos do ensino on-line e/ou híbrido. Já para os momentos síncronos, uma análise mais profunda das funcionalidades dos recursos de webconferência coloca o aluno numa condição de protagonista da sua própria aprendizagem, a partir de estratégias pedagógicas que proporcionem momentos de colaboração, construção e reflexões.

Outro ponto de destaque está na ampliação da intervenção docente que ao mesmo tempo que encoraja e oportuniza diferentes formas de aprender e refletir, flexibiliza momentos para que o aluno possa vivenciar situações práticas, tornando-o apto para que, de forma autônoma e crítica, possa recriar novo conceitos do que fora aprendido.

Diante desse contexto, ao observar os resultados individuais dos docentes participantes, pode-se explorar questões mais específicas de um determinado grupo de professores. Como dito, estar familiarizado com uso de ambientes virtuais não garante um nível de proficiência mais elevado. Ao recorrer ao instrumento, pode-se obter indicadores mais precisos de quais competências serão ne- 
cessárias para adoção de tecnologias digitais nas práticas pedagógicas destinadas às modalidades ofertadas no ensino superior (on-line, presencial e híbrida).

0 exemplo, a seguir, traz os resultados de uma amostra de 16 professores, escolhidos aleatoriamente, que participaram do presente estudo (TABELA 4). A função exercida pelo professor comparada aos resultados por competência em cada área, fornece com maior assertividade pontos que, do ponto de vista institucional e/ou até mesmo individual, merecem maior atenção, não limitando-se apenas às questões impostas pelo distanciamento social.

Tabela 4 - Resultados por competência X Perfil de atuação

\begin{tabular}{|c|c|c|c|c|c|c|c|c|}
\hline Perfil N & $\mathbf{N}$ & Área 1 & Área 2 & Área 3 & Área 4 & Área 5 & Área 6 & Total \\
\hline Tutor & 1 & B2 & B2 & B2 & B2 & B1 & C1 & B2 \\
\hline Tutor & 10 & C1 & A1 & B1 & A2 & B1 & A2 & B1 \\
\hline Tutor & 48 & B2 & B2 & B2 & B1 & B1 & B2 & B2 \\
\hline Tutor & 80 & A2 & A2 & B1 & A1 & A1 & A1 & A1 \\
\hline Professor EaD & 3 & C2 & C2 & C1 & C2 & C1 & B1 & B2 \\
\hline Professor EaD & 52 & B1 & B1 & B1 & A2 & B2 & B2 & B1 \\
\hline Professor EaD & 88 & A2 & B1 & A2 & A2 & B1 & A2 & A2 \\
\hline Professor EaD & 19 & B1 & A1 & B1 & A2 & B1 & B1 & B1 \\
\hline Prof. Presencial & 34 & B1 & A1 & C1 & B1 & B2 & C2 & B2 \\
\hline Prof. Presencial & 92 & C1 & C1 & C1 & B1 & B2 & C2 & B2 \\
\hline Prof. Presencial & 66 & C1 & B2 & C1 & B2 & C1 & C1 & B2 \\
\hline Prof. Presencial & 102 & A2 & B2 & B1 & A1 & A1 & B1 & A2 \\
\hline Prof. Híbrido & 5 & B2 & A1 & A2 & A1 & A1 & A2 & A1 \\
\hline Prof. Híbrido & 32 & B1 & B2 & C1 & B1 & B1 & C1 & B2 \\
\hline Prof. Híbrido & 56 & B2 & B2 & C1 & B1 & B2 & B2 & B2 \\
\hline Prof. Híbrido & 75 & B2 & B1 & C1 & B1 & C1 & B2 & B2 \\
\hline
\end{tabular}

Fonte: Adaptado de Dias-Trindade e Ferreira (2020).

Os resultados obtidos pelas amostras N80 (tutor), N88 (Professor EaD) e N5 (Professor de Cursos Híbridos) demonstram indicadores frágeis em quase todas as áreas de proficiência digital, tal comportamento, tende a ativar um sinal de alerta para que sejam realizadas ações formativas mais elevadas para subsidiar as lacunas identificadas no perfil docente com atribuição para atuação na modalidade de ensino, seja presencial, totalmente a distância ou de forma combinada. Neste sentido, como sugestão, pode-se criar programas de formação com níveis de complexidade, com intuito de 
explorar as tecnologias digitais operacionais da função, contemplando duas vias, a de ordem técnica (experimentar) e estratégias pedagógica (refletir em qual contexto se aplica).

Um outro ponto de destaque na Tabela 4, é de que nem todos os participantes carecem das mesmas formações nas Áreas. Como exemplo, tem-se os níveis dos participantes N1, N34, N92, N66, N32 para a Área 6 (Promoção das competências digitais dos estudantes). Cabe salientar, o que se observa, enquanto procedimento comum, a criação de programas de formação docente endereçados para atender um nicho de atuação, em se tratando do desenvolvimento de competências digitais, o instrumento corrobora para que os esforços sejam empenhados sob medida, atentando-se às três dimensões Competências Profissionais dos Professores, Competências pedagógicas dos professores e Competências dos estudantes.

Um olhar individual, tendo em vista as ações de sustentabilidade financeira sem perder de vista a qualidade de ensino, sobre as médias de valores mais baixos das competências digitais evidenciadas nas Tabelas 2 e 3, possibilita ainda, por exemplo, a instituição desenvolver internamente iniciativas para identificar professores multiplicadores que possam apoiar a criação de oficinas, a organização de comunidades virtuais de práticas pedagógicas, conhecidas também por EdTechs. 0 item Diferenciação e Personalização identificado neste estudo com menor indicador, permitiria a organização de formações específicas para abordar temas como: trilhas de aprendizagem adaptativa, personalização de ensino, estratégias para combinar os espaços de aprendizagem, uso avançado dos ambientes virtuais, avaliação e o engajamento dos estudantes em momentos síncronos e assíncronos.

Em uma visão de futuro, o mapeamento dos pontos de melhorias por meio do instrumento, possibilita direcionar esforços para modelos de formação mais personalizados. 0 repensar dos espaços de aprendizagem (on-line, presencial) conectado ao uso pedagógico das tecnologias digitais possibilitará elevar os indicadores institucionais para as competências essenciais que se deseja desenvolver nos estudantes. Tal afirmação reforça a ideia de que é necessário não apenas vencer os desafios de se ensinar remotamente, mas garantir que os processos de ensino e aprendizado apoiados pelas tecnologias digitais sejam ressignificados e tragam consigo uma essência pedagógica para cada utilização.

\section{CONCLUSÕES}

Ao longo dos últimos meses a expressão "novo normal" tem sido utilizada nos mais diversos meios e associada aos mais variados temas. No caso da Educação, este "novo normal” vem sendo referido em associação quer a pensamentos positivos, quer negativos sobre como será a Escola depois de passado o período de quarentena em que vivemos atualmente.

No texto de finais do século passado, Educação: um tesouro a descobrir, coordenado por Jacques Delors (1996, p. 21) era reconhecido que "a educação deve, pois, adaptar-se constantemente a estas transformações da sociedade, sem deixar de transmitir as aquisições, os saberes básicos frutos da experiência humana", servindo como bússola que permita navegar por meio da complexidade do mundo.

Nesse sentido, quando nos encontramos frente a uma situação adversa, um momento em que ninguém consegue verdadeiramente antecipar os cenários futuros, é necessário preparar os ambientes 
educativos para diminuir o mais possível a possibilidade de exclusão pelo digital. E essa exclusão pode acontecer não só do lado do estudante, mas também do professor. Assim, é fundamental compreender as necessidades de competência digital para criar ambientes educacionais de qualidade, pensados, sobretudo, para incluir a todos, onde o digital pode auxiliar no desenvolvimento de práticas de ensino e de aprendizagem e de todo um ecossistema educativo de elevada qualidade e onde todos tenham lugar.

Enquanto professores, para conseguir fazer esse esforço, diminuir as possibilidade de exclusão digital e construir com os estudantes ambientes digitais de aprendizagem (quer em períodos normais quer, como agora vivemos, em tempos de quarentena que nos retiram a possibilidade de ambientes presenciais ou híbridos) é necessário compreender como usar a tecnologia, em diferentes momentos do processo de ensino e de aprendizagem, não esquecendo também, e como lembra o DigCompEdu, a capacitação dos estudantes para o uso do digital.

É isso que o instrumento aqui apresentado possibilita: uma autoavaliação das competências digitais individuais para, a partir daí, traçar cenários formativos adequados às reais necessidades.

Do estudo apresentado e realizado em vésperas de quarentena por causa da pandemia do COVID-19, os resultados evidenciaram que áreas de competências mais fortes estão concentradas nos itens Competências Digitais, Prática Reflexiva pertencentes à Área 1; Aconselhamento, Ensino e Aprendizagem Colaborativa - Área 3 e Informação e literacia midiática, representada pela Área 6. Em destaque, constatou-se o item Competências Digitais (Área 1) com melhor média de pontuação. Esse item está relacionado ao indicador que demonstra a participação em programas de formação on-line. Considerando o perfil da amostra, pode-se dizer que os dados convergem com a realidade vivenciada pelos participantes por atuarem e tramitarem em modalidades de ensino presencial, on-line e híbrida.

Nessa sintonia, os dados coletados e os insights gerados pelo instrumento de Dias-Trindade e outros autores (2019) revelam que novos programas de formação docente poderão ser oportunizados, com a finalidade de vencer os desafios gerados pelo contexto da aprendizagem digital e as competências requeridas para elevar a qualidade dos processos de ensino e aprendizagem, permitindo saber quais áreas devem ser desenvolvidas com prioridade, evitando-se, assim, generalizações.

Em consequência, destaca-se que a personalização e o planejamento da formação docente, desenhada sob essa premissa, não habilita o professor apenas para atuar no ensino remoto emergencial, mas sim para o que se espera da educação com um meio de preparar os aprendentes para a vida numa sociedade hiperconectada.

\section{REFERÊNCIAS}

DELORS, J. (coord.). Educação: um tesouro a descobrir. Porto: Edições Asa, 1996.

DIAS-TRINDADE, S.; MOREIRA, J. A.; NUNES, C. Escala de autoavaliação de competências digitais de professores. Procedimentos de construção e validação. Texto Livre, v. 12, n. 2, p. 152-171, maio-ago. 2019. 
DIAS-TRINDADE, S.; FERREIRA, A. G. Digital teaching skills: DigCompEdu CheckIn as an evolution process from literacy to digital fluency. ICON014, v. 18, n. 2, 2020.

DIAS-TRINDADE, Sara; MOREIRA, J. A.; FERREIRA, A.G. Assessment of University Teachers on their digital competences. Qwerty-Open and Interdisciplinary Journal of Technology, Culture and Education, v. 15, n. 1, p. 50-69, 2020.

EU SCIENCE HUB. Learning and Skills for the Digital Era. Disponível em: https://ec.europa.eu/jrc/ en/research-topic/learning-and-skills. Acesso em: 20 jan. 2020.

FERDIG, Richard E. et al. Teaching, technology, and teacher education during the covid-19 pandemic: Stories from the field. Waynesville, NC, USA: Association for the Advancement of Computing in Education (AACE), 2020.

FLORIDI, Luciano. The Onlife Manifesto - Being human in a hyperconnected Era. Londres, Springer Open: 2015.

GARCÍA-PEÑALVO, F. J. et al. La evaluación online en la educación superior en tiempos de la COVID-19. Salamanca: Edição Universidade Salamanca, 2020.

MILLER, C.; BARTLETT, J. - 'Digital fluency': towards young people’s critical use of the internet. Journal of Information Literacy, v. 6, n. 2, p. 35-55, 2012.

PIMENTEL, F. S. C. et al. Atividades na pós-graduação utilizando as ferramentas digitais no contexto da crise da COVID 19: análise qualitativa descritiva. EmRede-Revista de Educação a Distância, v. 7, n. 1, 2020.

PRETTO, N.; RICCIO, N. - A formação continuada de professores universitários e as tecnologias digitais. Educar, v. 37, 2010

REDECKER, Christine et al. European framework for the digital competence of educators: DigCompEdu. Joint Research Centre (Seville site), 2017.

SPARROW, J. Digital Fluency: Big, Bold Problems. EDUCAUSEreview, 2018.

WHITE, G. K. Digital fluency: skills necessary for learning in the digital age. Melbourne: ACER, 2013.

ZABALZA, M. A. 0 ensino universitário: seu cenário e protagonistas. São Paulo: Artmed, 2004. 


\section{(). (1) (-)}

Este artigo é licenciado na modalidade acesso abertosob a Atribuição-Compartilhalgual CC BY-SA

2 Doutora em História; Professora, investigadora - Universidade de Coimbra, Centro de Estudos Interdisciplinares do Século XX, Faculdade de Letras (DHEEAA).

E-mail: sara.trindade@uc.pt

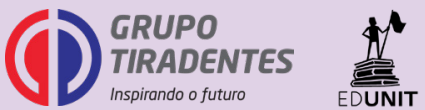

